\title{
JUVENILE DELINQUENCY PATTERN BY RORSCHACH INK-BLOTS
}

\author{
A. B. RAY
}

Calcutta University

The object of the present research is to compare some basic personality pattern of delinquents with that of non-delinquents and thereby attempt to describe a delinquency pattern by Rorschach Ink-blots.

\section{Method and Procedure.}

40 delinquents were selected randomly from a detention home for delinquents for experiment. They were between the age group of 12 years and 16 years. 40 non-delinquents were selected from public school boys. They were matched with the delinquents on the following criteria: 1) Age; 2) Sex (in this case, male); 3) Broad racial origin (Hindus, Muslims, Christians); 4) Economic level and residence in under-priviledged urban area.

The test used in the present investigation is Rorschach Ink-bolts. Individual history sheets were consulted which included family history, condition of residence, economic background and education, associates, etc.

The method of interpretation of the data was according to Mons, W. (4). Results.

Some significant differences in personality were found between the delinquent and non-delinquent groups, also some findings contradicted the findings of previous investigators to be discussed later on.

Table 1.

\begin{tabular}{c|ccccc}
\hline$\%$ of & W & D & $\mathrm{d}$ & $\mathrm{dd}$ & $\mathrm{ddd}$ \\
\cline { 2 - 6 } $\begin{array}{c}\text { Delinquent } \\
\text { Non-Delinquent }\end{array}$ & 11.8 & 65.5 & 11.1 & 11 & 3.5 \\
\hline
\end{tabular}

Table 3 .

\begin{tabular}{cc}
\hline W $: M$ & $(\mathrm{H}+\mathrm{A}):(\mathrm{Hd}+\mathrm{Ad})$ \\
\hline $21: 205$ & $8: 1$ \\
\hline $12.8: 7.4$ & $3: 1$ \\
\hline
\end{tabular}

Table 2.

\begin{tabular}{c|ccccccccccccccc}
\hline$\%$ of & $\mathrm{m}$ & $\mathrm{FM}$ & $\mathrm{M}$ & $\mathrm{K}$ & $\mathrm{k}$ & $\mathrm{FK}$ & $\mathrm{F}$ & $\mathrm{Fc}$ & $\mathrm{c}$ & $\mathrm{Cm}$ & $\mathrm{Km}$ & $\mathrm{FC}$ & $\mathrm{CF}$ & $\mathrm{C}$ \\
\hline Del & 3.5 & 11 & 4 & 4 & 0.2 & 4 & 55 & 0.8 & 0.5 & 2 & 2.5 & 7 & 6 & 7 \\
\hline Non-Del & 0.4 & 8 & 8 & 2 & 0.8 & 2 & 52 & 0.8 & 0 & 0 & 0.4 & 16 & 7 & 0 \\
\hline
\end{tabular}

Basic personality pattern - Comparatively higher $\mathrm{F} \%$ among delinquents (1st group) than non-delinquents (2nd group) suggests constriction or coarctation of personality of the 1st group. Although in this respect, delinquents cannot be regarded as significantly different from non-delinquents.

The personality pattern of the delinquent group cannot be regarded as balanced and well-adjusted. The E.B.s of the two groups are not different from each other.

Personality structure - Most of the delinquents in the sample are confused and loose in succession. The emotional balance of the delinquent group is impaired by the presence of 
primitive hostile inner forces and these are so numerous that there is always a possibility of violent outburst of emotions which indicates their emotional unstability, FC: $(C F+C)$, Table-2. This group is guided by emotions and impulses rather than by intellect. On the other hand, the non-delinquent group is found to be more stable emotionally.

(Table 1) indicates the conflict and inner hostile drives which is in excess in the delinquent group. These inner hostileforces are linked with anxiety $(\mathrm{Km}, \mathrm{Cm})$ (Table 2) and are obstructions to their adjustment to the environment. Their fantasy life is inadequate to meet with the large part of their emotions. On the contrary, the fantasy life of non-delinquent group is normally developed. Although delinquent group suffer from excess anxiety (K), there is also slight tendency to make it rationalise in touch with reality (FK) (Table 2).

The non-delinquent group suffers from less anxiety and they have the capacity to rationalise it (Table 2).

'W' responses indicate conceptual and creative thought. It suggests that the individual has a keen eye for the solution of the problem as a whole. The delinquent group gave lesser ' $W$ ' responses in comparison with non-delinquent group (Table 1).

The proportion W: D shows that the delinquents are more interested in the obvious issues of their life and have less capacity for conceptual and creative thought in comparison with non-delinquents. The two groups are not altogether different in their interest in petty matters $(d d+d d d)$ which is common to their age. The ' $d$ ' responses indicate that both the groups have their keen eyes around their environment (Table 1).

Mental activity - The proportion W:M (Table 3) points out the most unfavourable balance between the capacity for abstract thought and fantasy life in the case of delinquents. Their fantasy life is altogether immature. The excess of FM over $M$ in the case of delinquents shows their infantile urges. Their primitive drives are far greater than the fantasy can deal with (Table 2).

Intellectual level - The delinquents as a group are found to be less intelligent than the nondelinquents. This low intelligence may be due to over shadowing by the anxiety and primitive hostile inner forces.

Other factors for interpretation - The proportion $(\mathrm{H}+\mathrm{A}):(\mathrm{Hd}+\mathrm{Ad})$ shows lack of selfconfidence in the delinquents $(8: 1)$ whereas the nondelinquents have more confidence in their own judgement (Table 3). This indicates that the delinquents are more suggestive than the non-delinquents.

The $43 \%$ responses to the last three cards indicate that the delinquents are more susceptible to their environment than the non-delinquents.

The delinquents often show the signs of colour shock, neurosis, hysteria. Their responses are also very often included morbid, schizoid and anatomy responses which in many cases can be regarded as abnormalities. The non-delinquents gave few responses like these which in no case can be regarded as sufficient abnormality.

Analysis of the content - The variety of the content is poor in the delinquents and good in the non-delinquents. The fair amount of $\mathrm{d}, \mathrm{dd}$, ddd, responses show the infantile interest of both the groups which is not uncommon to their age group (Table 1). The nondelinquents gave more popular and original responses than the delinquents.

The delinquents as a group are hysteric and neurotic personalities and there is also some schizoid characteristics in some cases. 
The non-delinquents are almost free from them.

Discussion and Conclusion.

Zulliger (3) described a delinquency pattern which included three primary signs as follows:- i) A presence of confabulatory responses (DW). ii) A predominance of crude colour responses $(\mathrm{CF}+\mathrm{C})$ over $(\mathrm{M}+\mathrm{F} \mathrm{C}+$ shading responses $)$, and. iii) Ever present extratensive Erlebnistyp.

He also indicated four secondary syndrome symptom which are usually present in the delinquents: (a) Confused or loose succession, (b) a strong component of white space responses (c) a high $\mathrm{A} \%$, (d) a low $\mathrm{H} \%$.

Kelly and Flicker (3) found abnormal proportions of W and D; FM predominates over $M$, and a marked aggression is usually shown in the content.

Beck (1) found delinquents in general tend to show a decrease in colour responses suggesting constriction with an average number of extratensive trends. These children show constricted psychic potentialities, a tendency to rigid adherence to form, increase in $\mathrm{Hd}$, Ad, $\mathrm{D}$ and shading responses. Beck felt that these children are suffering from anxiety attitudes and inadequate personality development.

In agreement with Beck, the present author also found that the delinquents suffer from inadequate personality development and anxiety attitudes, increase in Ad and shading responses and FM predominates over $M$ found by Kelly and Flicker.

Unlike Zulliger, the present author found no difference between the two groups in E. B. S. No sufficient confabulatory and strong component of white space responses were found in the delinquents as suggested by Zulliger. $\mathrm{D} \%$ was within the normal range.

Ray and Majumdar (5) found decrease in $W$ responses, FM predominates over $M$, high $\mathrm{A} \%$ and low $\mathrm{H} \%$ in the delinquents which are in agreement with the present investigation.

Like Endacot (2) the present author also found lower $\mathrm{R}$ and lower $\mathrm{M}$ in the delinquents. But in contrast to him the present author found high $\mathrm{F} \%$, frequent shading responses, high $\mathrm{A} \%$ and low $\mathrm{H} \%$ in the delinquents.

In conclusion, the delinquency pattern may be described in the following way on the basis of present investigation:
(a) Confused or loose succession
(e) FM predominates over $\mathrm{M}$.
(b) Total number of responses lowered
(f) $(\mathrm{CF}+\mathrm{C})$ predominates over $\mathrm{FC}$.
(c) High F - \%
(d) Decrease in $\mathrm{W}$ responses.
(g) High $\mathrm{A} \%$ and low $\mathrm{H} \%$
(h) Low intelligence.

\section{REFERENCES}

1. Beck, S. J. (1937) Introduction to Rorschach Method: A manual of personality study. Amer. Orthopsychint. Assoc. Monog. 1.

2. Endacott, J. L. (1941) The results of hundred male juvenile delinquents on the Rorschach ink-blot Test. J. crim. Psychopath., 3, 41-50.

3. Klopfer, B and Kelly, D.M. (1946). The Ror- schach Technique. World Book Co.

4. Mons, W. (1950) Principles and practice of the Rorschach personality test. London: Faber and Faber Ltd.

5. Ray, A.B. and Majumdar, A. K. (1962) Latent personality content of juvenile delinquents. $J$. of psychol. Researches, 6, 1, 7-8.

Ms. reccived VIII 30 '63. 